\title{
An Adaptive Learning Mode of "Public Psychology" Based on Creative Thinking with Virtual Simulation Technology
}

\author{
https://doi.org/10.3991/ijet.v15i23.18957 \\ Chengchun Shen, Aili Qi ${ }^{(凶)}$ \\ Guizhou University of Engineering Science, Bijie, China \\ qiailili@yeah.net
}

\begin{abstract}
Due to the outbreak of COVID-19, the teaching of psychology in college has become especially important, posting higher requirements on the teaching content and purpose of the course of psychology. Nowadays, the traditional course of public psychology in college only focuses on the prevention and correction of psychological problems among college students, but educators ignore the importance of teaching students to understand psychological problems through relevant courses, making it impossible to achieve the expected effect of mental health education for students. Colleges should apply the notion of positive mental health education in the course of public psychology designed for college students. Students can better adapt to the society only when they have sound mental quality. According to requirement of "the zone of proximal development" a conceptual framework of the course was established in this study based on adaptation theory in which students are encouraged to think independently, as required by and an autonomous learning situation was created for students with psychological problems. At the same time, the education and teaching programming software named Scratch was adopted and integrated in the virtual simulated experimental teaching system of psychology. The integrated teaching system included the management of psychological teaching software, the monitoring of psychological experimental process, the query and analysis of psychological experimental data and the management of academic experimental resources, forming an integrated teaching environment with adaptive learning functions. In the end, the ant colony algorithm was used to mine a learning mode that is commensurate with the learner's knowledge level, meets the learner's resource preferences and satisfies the learner's needs for learning activities, and this learning mode was identified as the best application mode for the learning of public psychology. It was revealed in practice that the adaptive learning mode of psychology based on virtual simulation technology can improve students' learning initiative for the course of public psychology and increase their independent innovation ability.
\end{abstract}

Keywords—Virtual simulation technology; Adaptive; Creative thinking; Psychology 


\section{Introduction}

The outbreak of coronavirus disease 2019 (COVID-19) exerted a great impact on people's production and life and also posed a new challenge to the education industry. In the face of public health emergencies, how schools should ensure the teaching quality of courses and focus on cultivating students' core qualities, and how teachers should change their roles in order to adapt to the challenges of online education are problems and challenges confronting all educators. College students are at a crucial stage of the maturity and switch of psychology. In a manner of speaking, in this stage, college students are gradually matured, but as a matter of fact, they don't have a fully mature psychological state, so in this stage, college students are prone to more psychological problems [1]. The teaching purpose of public psychology is to help college students grow up healthily in psychology. This course is very conducive to the comprehensive development of college students. However, up to now, there are still some deficiencies in the course of psychology offered in the colleges. Although generally speaking, the teaching contents of public psychology are theoretical knowledge, and the knowledge is very extensive, most of the teaching equipment and mode are single and simple [2]. In addition, most teachers fail to cite practical cases in real life in the classroom, and students also fail to fully absorb the theoretical knowledge, which leads to a gradual decline in students' learning interest.

Virtual simulation technology is a technology that builds a virtual system by using computer software and simulates the real world, relying on modern information technologies, such as multimedia technology, simulation technology and network communication technology [3]. It is also known as virtual reality technology or simulation technology. Currently, virtual simulation technology has been widely applied in many fields, such as industry, agriculture, transportation, military affairs, education and medical treatment [4]. For this reason, during the teaching of the course of public psychology in colleges, we can try blending virtual simulation technology with psychology teaching, with the purpose of promoting the overall teaching quality of public psychology among college students.

Based on the characteristics of the course of public psychology, adaptive teaching method was introduced to the course, virtual simulation technology was integrated with multimedia teaching method, and a new adaptive modern information teaching mode for psychology was established in this paper. On the other hand, to cultivate students' creative thinking [5], during the teaching practice, a new virtual simulation software, Scratch programming software, was applied for the first time, and a learning performance evaluation system that was fit for this teaching mode was set up. The aim was to understand the previous knowledge level of college students of public psychology in advance, especially to analyse the features of students with poor grades, pay close attention to those with poor grades and weak knowledge level in the early stage of the course and give targeted remedial measures to them, to ensure the learning effect after the new teaching mode was applied to the course of public psychology. 


\section{State of the Art}

Public psychology originated from western countries. So, the major of public psychology was established early in developed countries. The training goal, educational mode and assessment standard have been programmed and systematized. For example, Rittle [6] suggested integrating the education of computer literacy in the course of psychology. Undergraduates in a research design course were taught to program microcomputers for the control of experimental tasks. To promote general computer literacy, the training used a database management system with a full programming language. And experimental results indicated that this integrated teaching method was favourable for the all-round development of students. Goomas et al. [7] also suggested integrating library information technology in the course of psychology, and guide students to search, evaluate and use research data in the library in the process of teaching, to study and learn the psychology topics. They reported documents the process by which the El Centro College (Dallas County Community College District) librarians and the psychology faculty collaborated in bringing information and research skills into the psychology curriculum. As evidenced by an experiment, this teaching method was well-received by the students. During the practice teaching of psychology, Raupp \& Cohen [8] tried taking "volunteer services" as the practice content of psychology. Their study held that the course of psychology should encourage service practice in the community. As evidenced by teaching practice, this practice mode can help enhance students' ability to understand knowledge. Song [9] suggested blending two teaching modes: case teaching and scenario simulation, and applying them in the teaching of nursing psychology and drew a conclusion that this teaching mode can promote students' understanding of knowledge. By applying Bloom's taxonomy of educational objectives, Xu [10] designed a teaching process for psychology, and classified teaching objectives, teaching activities and assessment using "classification tables". The experimental results showed that it would be easier for this teaching method to achieve the teaching purpose.

"Adaptive learning system" [11] means that we can establish an intelligent learning environment which was able to arrange proper course contents and learning materials according to different learning conditions and features of students, and can give timely feedback. At first, it was a key development direction for intelligent learning and received high attention from the international educational community [12]. Under the condition of rapid development of modern education, the adaptive learning mode has been practiced and applied in the teaching of multiple disciplines in different countries. Nevertheless, up to now, there are no reports on the application of adaptive learning mode in the course of public psychology.

In view of this, based on the adaptive learning model, by associating with the virtual simulated experimental teaching platform in an innovative way, this paper integrated the functions of the management of psychological teaching software, the monitoring of psychological virtual experimental process, and the management of academic resources, etc. into one. On the other hand, for the first time, Scratch, a kind of children's programmed education software, was applied to the virtual simulated 
experiment platform to help teaching. To integrate children's programmed education in subject teaching was a new attempt for changing and reshaping the concept of computational education. Hopefully, our study can serve as an objective reference for the teaching of public psychology, better help college students master psychology knowledge while improving their creative thinking, to achieve the teaching purpose of public psychology.

\section{$3 \quad$ Adaptive Learning Mode in Teaching Based on Virtual Technology}

\subsection{To blend frame-based teaching in psychology}

The frame-based teaching of psychology is to blend frame-based teaching into psychology and build a conceptual framework of this course, according to the requirements of "zone of proximal development", centred on the current topic of public psychology. First of all, teachers need to introduce students to a particular situation with psychological problem and give them enough time to think things out for themselves. This includes determining all kinds of attributes related to a given psychological concept and sort all kinds of attributes of psychology in sequence of importance. At the beginning of the course, the teachers should first lead students into the situation of the lesson, and then ask them to analyse the situation by themselves. When the student's inquiry, teachers should give them some tips in due time and mobilize their creative thinking. See Fig. 1 for the concrete integrated framework.

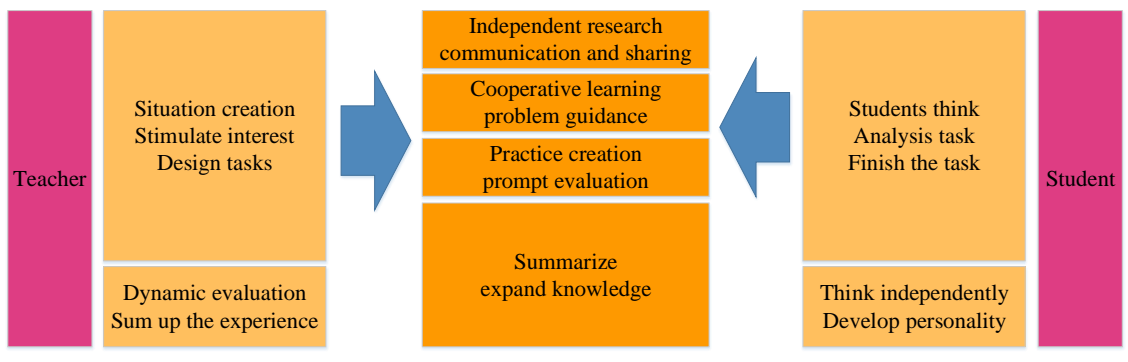

Fig. 1. Frame-based Teaching of Psychology

\subsection{Application of virtual simulation technology in adaptive learning mode}

The adaptive learning virtual simulated experimental teaching platform proposed in this study can solve problems in the construction, integration, opening and sharing, etc. of resources in the field of virtual simulated experimental teaching, using such technologies as virtual reality, multimedia, man-machine interaction, database and network communication and real-time monitoring, recording and broadcasting, etc., facilitate the management of virtualized experimental application, sharing of experimental academic resources, virtual simulated experimental teaching, analysis 
and query of experimental data, etc., and expand the "limited space for physical experiment teaching " into "infinite space for virtual experiment teaching", so as to fulfil the opening and sharing of virtual simulated teaching resources. For details, see Fig. 2 below.

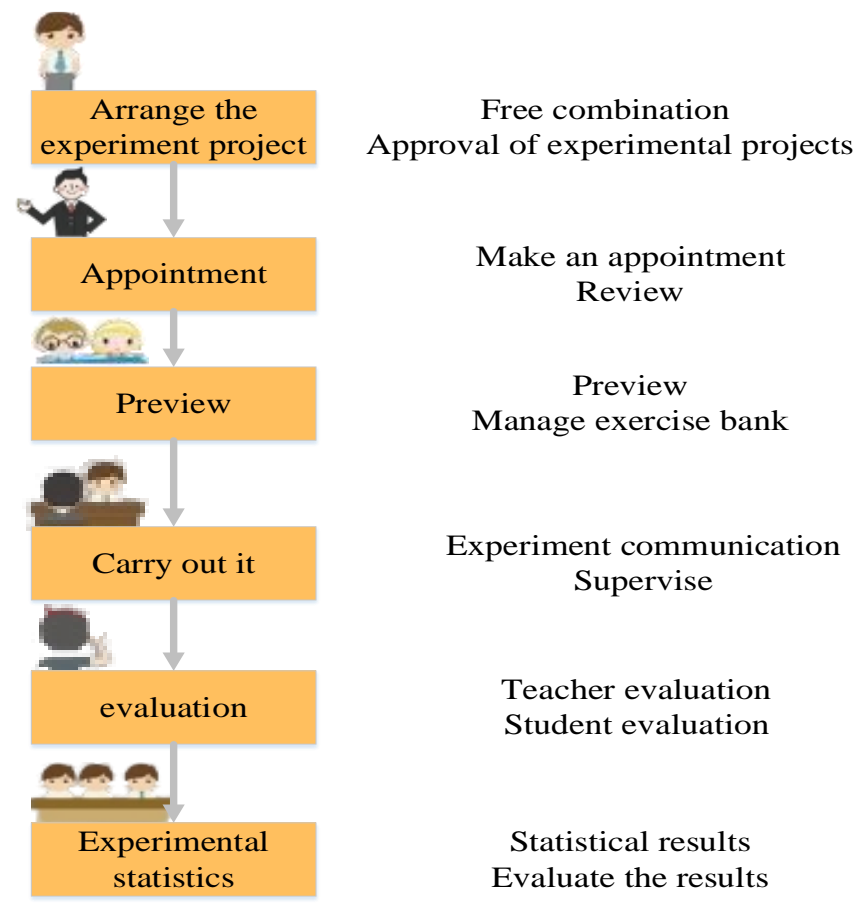

Fig. 2. Virtual Simulated Experimental Teaching Platform for Adaptive Learning

\subsection{Application of virtual technology and scratch software in adaptive learning}

Fig. 3 showed the process of applying Scratch software to virtual simulation technology and constructing an adaptive learning mode model. As a carrier to implement children's programmed education, Scratch was both instrumental and educational [13], which can be used as a horizontal tool for course teaching, in order to integrate appropriate contents of subjects and units, and foster students' abilities in theoretical thinking, subject knowledge, academic motivation and social emotions, etc. [14]. A showcase of the application of Scratch programming software was shown in Fig. 4. 


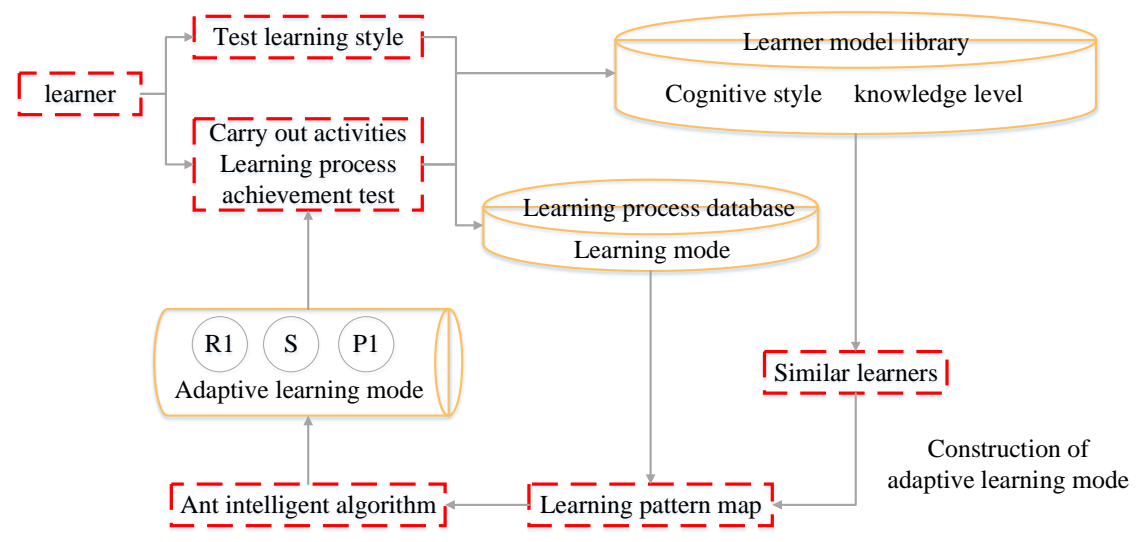

Fig. 3. Construction of a Model with the Adaptive Learning Mode of Scratch Software

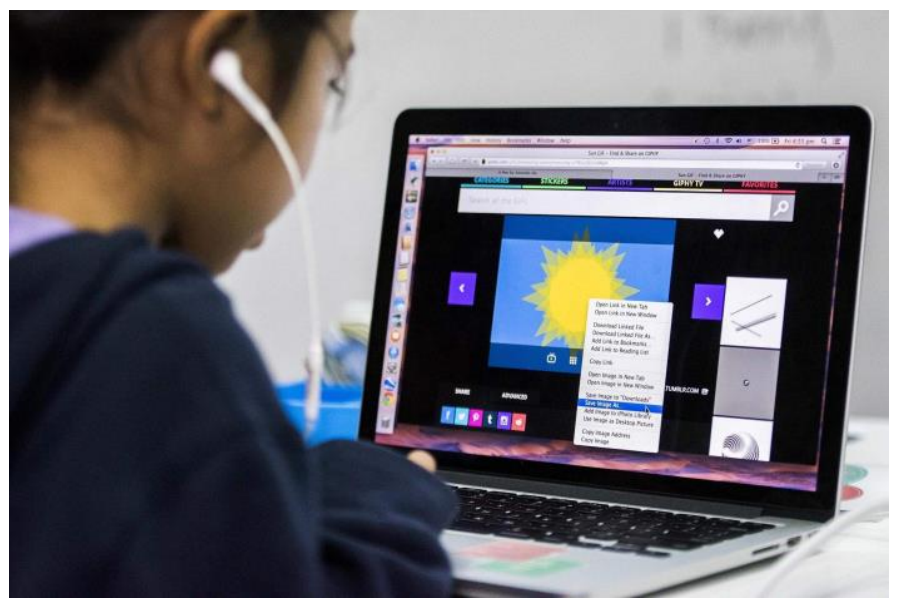

Fig. 4. A Showcase of the Application of Scratch Programming Software

In the present study, first of all, taking the personalities and traits of each student as templates, teachers looked for similar learners in the student database, and generated a learning mode map in line with the historical learning modes of public psychology retained by similar learners in the database and test scores of public psychologies. With an ant colony intelligent algorithm, a learning mode commensurate with the learner's knowledge level, conformed to his resource preferences and satisfied his needs for learning activities was mined from the learning mode map of public psychology, to achieve the adaptive learning mode of public psychology. Meanwhile, many factors should be taken into account when the practice was carried out. Whether teachers can blend Scratch media environment or programming principles with appropriate subject knowledge, the starting time of the teaching that integrated programmed education with subject, the support of technical equipment, as well as the 
technical proficiency of teachers and students, etc. were also factors warranting further discussion.

\subsection{Implementation process of virtual simulation technology in adaptive learning mode}

In this study, the online learning behaviours (e.g. browsing resources and taking tests, etc.) of learners were first classified into 8 categories, and corresponding mapping methods were specified. The contents to which learning behaviour were mapped included searching resources, forum discussion, tests, exercise, summary, cooperation, case analysis and others. After that, virtual simulation technology was adopted to sort the learners' behaviours, and the original learning behaviour data were converted to learning mode data. From two dimensions, that is, cognitive style and knowledge level, the personality vector of learners $S=\{\mathrm{s} 1, \mathrm{~s} 2, \mathrm{~s} 3, \mathrm{~s} 4, \mathrm{k} 1, \mathrm{k} 2, \ldots, \mathrm{kn}\}$ was defined, where s1, s2, s3 and s4 were the values of four dimensions of the FelderSilverman learning style model. Through numerical transformation, each dimension was divided into six discrete grades from small to large and denoted by digits 1 to 6 respectively. Also, the learner's knowledge level was divided into 6 grades: to memorize, understand, use, analyse, synthesize and evaluate, which were also expressed by digits 1 to 6 in turn. The similarity between learners was calculated by Pearson's correlation coefficient and the calculation method was shown in Eq.(1). Where $\operatorname{sim}(\mathrm{u}, \mathrm{v})$ stood for the similarity between learner $\mathrm{u}$ and learner $\mathrm{v}$, sui represented the component of the personality vector $i$ of learner $u$, and su represented the average of all personality vectors of learner $u$. According to the value range of Pearson's correlation coefficient, the values of the similarity $\operatorname{sim}(\mathrm{u}, \mathrm{v})$ between learners were between -1 and +1 . Sim $(u, v)>0$ suggested that two learners were positively similar, $\operatorname{sim}(\mathrm{u}, \mathrm{v})<0$ indicated that two learners were negatively similar, and the greater absolute value of $\operatorname{sim}(u, v)$, the stronger similarity. For example, the personality vectors of learners $u$ and $v$ were $S u=\{1,2,2,4,2,2,3\}$ and $S v=\{2,2,3$, $4,2,3,3\}$ respectively. The similarity between two learners can be calculated by Eq. (1), as follows:

$$
\operatorname{sim}(u, v)=\frac{\sum_{i \in S}\left(S_{u i}-\overline{S_{u}}\right)\left(S_{v i}-\overline{S_{v}}\right)}{\sum_{i \in S}\left(S_{u i}-\overline{S_{u}}\right)^{2} \sum_{i \in S}\left(S_{v i}-\overline{S_{v}}\right)^{2}}
$$




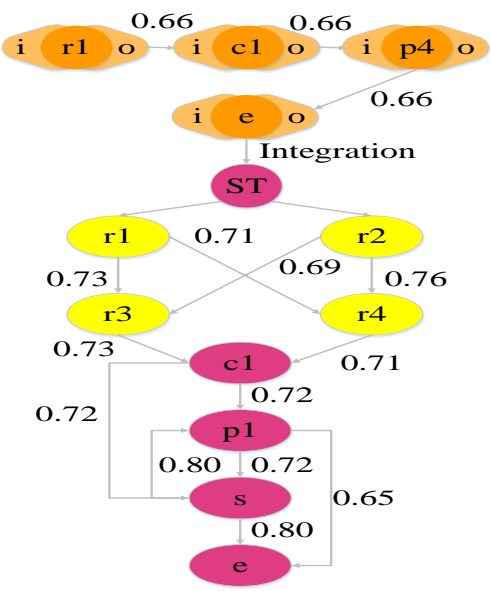

Fig. 5. Construction of an Adaptive Learning Mode Map of Public Psychology Based on Virtual Simulation Technology

From Fig. 5, it can be learned that a learning mode map was a set of all learning modes from the beginning of learning to the end of test. In this paper, a learning mode map was built by extracting the historical learning modes and test scores of similar learner groups. Among them, nodes corresponded to learners' learning behaviours, the directed arrow symbolized the transfer of learning behaviour, and the number on the arrow was the transfer weight, indicating the validity of this transfer. For each path, this study stipulated that their transfer weights should be identical and equal to their corresponding test scores. The learning modes of all similar learner groups were integrated as a whole and a learning mode map was built, as shown in the right part of Fig. 4. Where ST was a virtual node, which signified the initial node of learning, and E (test) signified the end point of the learning of knowledge unit, and the transfer weight of learning behaviours was the weighted average of multiple similar learners with respect to this transfer weight. The calculation method was shown in Eq. (2). In the expression, xy stood for the transfer of learning behaviour from $\mathrm{x}$ to $\mathrm{y}$, which symbolized the transfer weight of learner $u$ with respect to $x y, x y . \operatorname{sim}(u, v)$ stood for the similarity between learners $\mathrm{u}$ and $\mathrm{v}$, and $\mathrm{N}$ stood for a set of all similar learners.

$$
w_{x y}^{u}=\frac{\sum_{v \in N} \operatorname{sim}(u, v) \times w_{x y}^{v}}{\sum_{v \in N} \operatorname{sim}(u, v)}
$$

In this study, an improved ant colony algorithm was adopted to dig out the best or better path in the learning mode map. The basic idea was as follows: the walking path of ants was used to represent the feasibility of the problem to be optimized, and all paths of the whole ant colony constituted the space of problems to be optimized. Ants with shorter paths released a greater number of pheromones. With the passage of time, the pheromone concentration accumulated on shorter paths was gradually higher, and more and more ants chose this path. Ultimately, the whole ant colony 
would be concentrated on the best path under positive feedback. In this case, the corresponding path was the best solution to this problem.

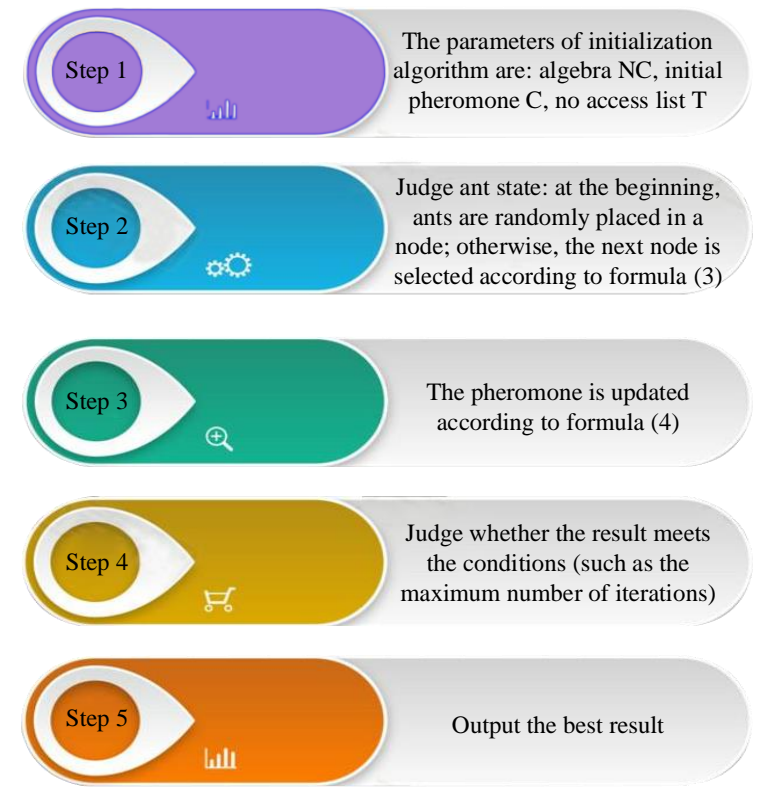

Fig. 6. Diagram of Ant Intelligent Algorithm

The flowchart of this ant colony algorithm was shown in Fig. 6. In this algorithm, the nodes corresponded to the learning behaviour nodes in the learning mode map, where Eq.(3) was the probability that ant $\mathrm{k}$ selected to enter node $\mathrm{j}$ from node $\mathrm{i}$ at time $t$; $\eta \mathrm{ij}(\mathrm{t})$ stood for the amount of heuristic information between node $\mathrm{i}$ and node $\mathrm{j}$ at time $t$, and generally speaking, its value was the reciprocal of the path weight between node $\mathrm{i}$ and node $\mathrm{j} ; \tau \mathrm{ij}(\mathrm{t})$ stood for the pheromone concentration from node $\mathrm{i}$ to node $\mathrm{j}$ at time $\mathrm{t} ; \alpha$ and $\beta$ stood for the influence degrees of pheromone concentration and amount of heuristic information on the probability of path selection; $\gamma \mathrm{j}$ was a penalty coefficient, Tk was a set of feasible nodes that ant $k$ hadn't visited by time $t$.

$$
p_{i j}^{k}(t)= \begin{cases}\left(\tau_{i j}(t)\right)^{\alpha} \times\left(n_{i j}(t)\right)^{\beta} \times \gamma_{j}, & \text { if }\left(j \in T_{k}\right) \\ 0 & \text { if }\left(j \notin T_{k}\right)\end{cases}
$$

As some of the path combinations in the learning mode map didn't necessarily meet this dependency, a penalty coefficient $\gamma \mathrm{j}$ was introduced to this study, which meant that node $\mathrm{j}$ was taken as the penalty coefficient for the next node. The calculation method was shown in Eq. (4). Where Ii and Oi stood for the dependency conditions of node $\mathrm{j}$, and I represented all existing nodes in the path (i.e. all nodes before node $\mathrm{j}$ ). 


$$
\gamma_{j}= \begin{cases}1, & \text { if }\left(I_{j} \subseteq \sum_{i \in i}\left(I_{i} \cup O_{i}\right)\right) \\ 0, & \text { if }\left(I_{j} \not \subset \sum_{i \in i}\left(I_{i} \cup O_{i}\right)\right)\end{cases}
$$

As suggested in Eq. (5), the pheromone concentration on the path from node $\mathrm{i}$ to node $\mathrm{j}$ was affected by the number of ants traversing the path. The more ants traversing the path, the greater pheromone concentration on the path. From Eqs. (3) and (4), it can be seen that the greater pheromone concentration on the path, the greater probability that the next ant would select this path. An increasingly intensified positive cycle was formed in this way:

$$
\tau_{i j}(t+1)=(1-\rho) \times \tau_{i j}(t)+\sum_{k=1}^{m} \Delta \tau_{i j}^{k}(t)
$$

\section{Teaching Example and Effect}

\subsection{Teaching example}

According to the design of Scratch program, all elements were integrated as an organic whole to build a teaching mode of public psychology, as shown in Fig. 7. In the most basic level of life, "cells", 4P learning method served as "genes" and regulated the ecosystem of the whole cell. The teaching environment, teaching subjects and social resources undertook the monitoring and boundary functions of "karyotheca", and design and learning were performed against this context. Four stages played the role of "mRNA", connected theory with practice and linked the theoretical "gene" of the topic with the "protein" of classroom practice and implementation. The teaching practice required more specific and detailed guidance. For this reason, under four stages, that is, abstraction by defining, algorithm design, iterative implementation, expansion and extension, the teaching stage was subdivided into target tasks, content presentation, design concept, learning guidance, iterative innovation, exercise feedback, assessment and consolidation, knowledge transfer, etc. Each stage corresponded to two steps, as shown in Fig. 7. The teacher explained the target tasks to the students, presented the knowledge, set up a problem situation, formed the representation of problems and helped students recall and bond Scratch algorithm with subject knowledge. Students designed and conceived algorithm steps in order to solve the problems: determined the ultimate solution by constantly trying to repair and implement iteratively, presented the resulting project, carried out peer communication, exhibition and online assessment and tried to expand the logical knowledge and elaborative faculty to a broader field of life and study. Scratch can better help college students understand the logical laws of psychology, as well as the scope and methods of data statistics. Taking the course of public psychology in colleges as an example, the present study selected a lesson to make a teaching design, in the hope of offering description and reference for the teaching mode of public psychology. As a basic, comprehensive and practical course, public psychology occupied an important position in higher education. The new curriculum standard advocated integrating the teaching of science with multiple disciplines and 
emphasized combining technology with psychological domain in scientific content. Fig. 8 below showed the teaching process of the adaptive learning mode of psychology based on virtual simulation technology. Fig. 9 demonstrated the practical applications of adaptive learning mode in public psychology.

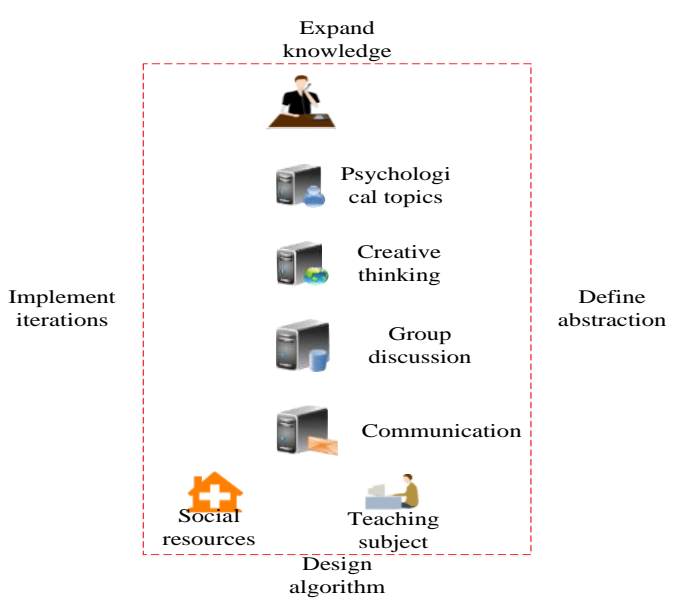

Fig. 7. The Teaching Mode of Public Psychology Designed by Scratch Program Designed by Scratch Program
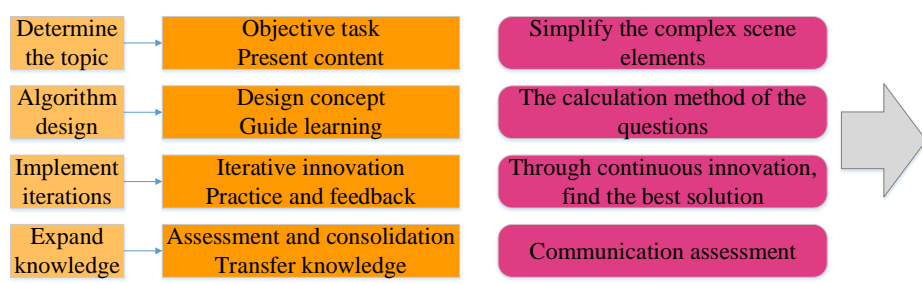

Fig. 8. Teaching Process of Adaptive Learning Mode of Psychology Based on Virtual Simulation Technology

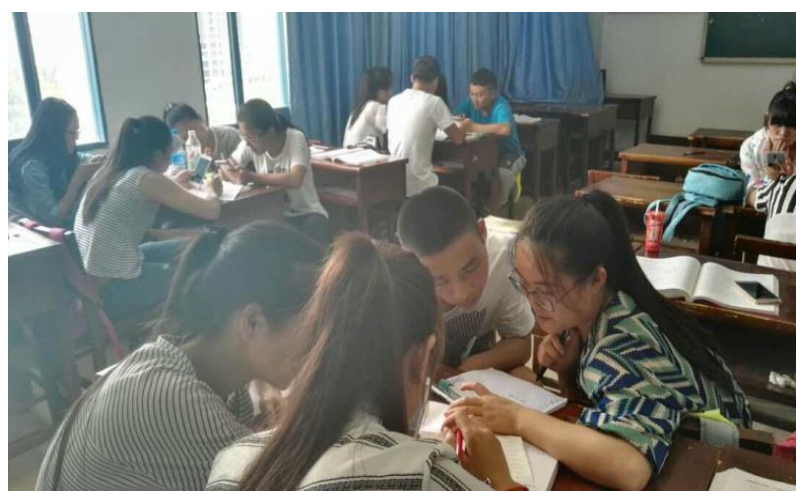

Fig. 9. Practical Applications of Adaptive Learning Mode in Public Psychology 


\subsection{Teaching effect}

In this study, from classes who took the course of public psychology in a given university in China, two classes were randomly selected as the experimental class and control class respectively, to compare the teaching effect. There was a total of 42 students in the experimental class and 42 valid questionnaires were recovered, with a recovery rate of $100 \%$. There was a total of 39 students in the control class and 39 valid questionnaires were recovered, with a recovery rate of $100 \%$. Students joined in an anonymous questionnaire survey, including 5 survey items, and then a t-test was performed on the scores filled in by the two groups and the teaching effect of the two groups was compared objectively. The survey results of the experimental class and control class were shown in Table 1.

Table 1. Survey Results of Students in the Experimental Group and Control Group

\begin{tabular}{|l|c|c|c|c|c|}
\hline \multicolumn{1}{|c|}{ Group } & $\begin{array}{c}\text { Learning } \\
\text { Initiative }\end{array}$ & $\begin{array}{c}\text { Academic } \\
\text { Performance }\end{array}$ & $\begin{array}{c}\text { Creative } \\
\text { Thinking }\end{array}$ & $\begin{array}{c}\text { Collaboration and } \\
\text { Communication }\end{array}$ & $\begin{array}{c}\text { Group } \\
\text { Discussion }\end{array}$ \\
\hline $\begin{array}{l}\text { Experimental } \\
\text { group ( } \mathrm{n}=42)\end{array}$ & $82.3 \pm 7.2^{*}$ & $84.1 \pm 5.4^{*}$ & $81.6 \pm 5.9^{*}$ & $83.4 \pm 6.2^{*}$ & $81.9 \pm 6.7^{*}$ \\
\hline $\begin{array}{l}\text { Control group } \\
\text { (n=39) }\end{array}$ & $76.4 \pm 8.9^{*}$ & $77.8 \pm 8.2^{*}$ & $72.6 \pm 7.4^{*}$ & $78.5 \pm 7.6^{*}$ & $76.1 \pm 8.1^{*}$ \\
\hline $\mathrm{t}$ & 4.83 & 4.96 & 4.82 & 4.67 & 4.98 \\
\hline
\end{tabular}

Note: * represented $\mathrm{P}<0.05$, compared with the control group

According to the statistical survey results of this study, the average score of students in the experimental group in terms of learning initiative was higher than that of the control group, and the subsequent variance was also smaller than that of the control group. Students in the experimental group performed better than those in the control group in terms of the other four aspects, such as collaboration and communication, creative thinking and academic performance, etc. Practice indicated that the adaptive learning mode of psychology based on virtual simulation technology can improve students' learning initiative for the course of public psychology and improve their independent innovation. As for the reasons, first of all, the experimental modules constructed by the adaptive learning mode can help students master the skills, methods and approaches of professional experiments, because the content systems included research and innovation experiments, comprehensive design experiments and construction of basic experiments. While the practice and training modules can deepen students' understanding of professional knowledge and promote their interest in the subjects. It is conducive to the fostering of students' professional skills. Secondly, the virtual simulation experience designed by Scratch program allowed students to complete the preview and review of psychology continuously and autonomously in the learning process, trained their abilities to understand and apply professional knowledge, inspired them to set up creative thinking in practice, guided them to select novels topics with social research value for in-depth research in practice, and encouraged them to communicate with each other. This kind of flexible and diversified learning mode not only raised students' learning interest and facilitated their coordination and communication, but also perfected students' 
characters and personality, in order to achieve the purpose of grasping and applying knowledge.

\section{Conclusion}

According to the statistical survey results of this study, the average score of students in the experimental group in terms of learning initiative was higher than that of the control group, and the subsequent variance was also smaller than that of the control group. Students in the experimental group performed better than those in the control group in terms of the other four aspects, such as collaboration and communication, creative thinking and academic performance, etc. Practice indicated that the adaptive learning mode of psychology based on virtual simulation technology can improve students' learning initiative for the course of public psychology and improve their independent innovation. As for the reasons, first of all, the experimental modules constructed by the adaptive learning mode can help students master the skills, methods and approaches of professional experiments, because the content systems included research and innovation experiments, comprehensive design experiments and construction of basic experiments. While the practice and training modules can deepen students' understanding of professional knowledge and promote their interest in the subjects. It is conducive to the fostering of students' professional skills. Secondly, the virtual simulation experience designed by Scratch program allowed students to complete the preview and review of psychology continuously and autonomously in the learning process, trained their abilities to understand and apply professional knowledge, inspired them to set up creative thinking in practice, guided them to select novels topics with social research value for in-depth research in practice, and encouraged them to communicate with each other. This kind of flexible and diversified learning mode not only raised students' learning interest and facilitated their coordination and communication, but also perfected students' characters and personality, in order to achieve the purpose of grasping and applying knowledge.

\section{Acknowledgement}

This work was supported by undergraduate natural science research project of Education Department of Guizhou Provincial (KY Zi [2013] No.204).

\section{$7 \quad$ References}

[1] Taylor, S.A., Hunter, G.L., Melton, H., \& Goodwin, S.A. Student engagement and marketing classes. Journal of Marketing Education, 2011, vol. 33(1), pp. 73-92. https://doi. org $/ 10.1177 / 0273475310392542$

[2] Di Masso, A. (2012). Grounding citizenship: Toward a political psychology of public space. Political Psychology, vol. 33(1), pp. 123-143. https://doi.org/10.1111/j.14679221.2011.00866.x 
[3] Van Bruwaene, S., Schijven, M.P., \& Miserez, M. Assessment of procedural skills using virtual simulation remains a challenge. Journal of Surgical Education, 2014, vol. 71(5), pp. 654-661. https://doi.org/10.1016/j.jsurg.2014.01.005

[4] Wang, X., Hao, Z., Luo, S., \& Ren, M. A Teaching Model of Urban and Rural Planning Curriculum Integrating Virtual Simulation Technology. International Journal of Emerging Technologies in Learning, 2018, vol. 13(6), pp. 149-162. https://doi.org/10.3991/ijet.v13i0 $\underline{6.8584}$

[5] Rudyanto, H.E., Ghufron, A., \& Hartono, H. Use of Integrated Mobile Application With Realistic Mathematics Education: A Study to Develop Elementary Students' Creative Thinking Ability. International Journal of Interactive Mobile Technologies, 2019, vol. 13(10), pp. 19-27. https://doi.org/10.3991/ijim.v13i10.11598

[6] Rittle, R.H. Computer Literacy in the Psychology Curriculum: Teaching a Database Language for Control of Experiments. Teaching of Psychology, 1990, vol. 17(2), pp. 127129. https://doi.org/10.1207/s15328023top1702_17

[7] Goomas, D.T., Baker, L., \& Weston, M.B. Critical Information Literacy Within the El Centro College Psychology Curriculum. Community College Journal of Research and Practice, 2015, vol. 39(1), pp. 95-99. https://doi.org/10.1080/10668926.2013.836690

[8] Raupp, C.D., \& Cohen, D.C. “A Thousand Points of Light” Illuminate the Psychology Curriculum: Volunteering as a Learning Experience. Teaching of Psychology, 1992, vol. 19(1), pp. 25-30. https://doi.org/10.1207/s15328023top1901_5

[9] Song, R.L. Application of case teaching and scene simulation teaching in nursing psychology teaching. Chinese Journal of Practical Nervous Diseases, 2010, vol. 13(14), pp. $10-11$.

[10] Xu, Y. Application of Bloom's education objective taxonomy in nursing psychology teaching. Chinese Nursing Research, 2014, vol. 38(35), pp. 4480-4481.

[11] Alameen, A., \& Dhupia, B. Implementing Adaptive e-Learning Conceptual Model: A Survey and Comparison with Open Source LMS. International Journal of Emerging Technologies in Learning, 2019, vol. 14(21), pp. 28-45. https://doi.org/10.3991 lijet.v14i21.11030

[12] Yaghmaie, M., \& Bahreininejad, A. A context-aware adaptive learning system using agents. Expert Systems with Applications, 2011, vol. 38(4), pp. 3280-3286. https://doi.or g/10.1016/j.eswa.2010.08.113

[13] Wang, L.G., Bu, A.X., Liu, K.J., Zhang, J.W. The Application of the First Principles of Instruction in the Teaching of Basic Theory of Traditional Chinese Medicine for Postgraduate. Chinese Medicine Modern Distance Education of China, 2019, vol. 17(4), pp. 145-147.

[14] Liu, X.Y. Application example of Maple Software animation function in higher mathematics teaching. Journal of Shaoyang University (Natural Science Edition), 2019, vol. 16(2), pp. 89-95.

\section{Authors}

Chengchun Shen is an associate professor in Guizhou University of Engineering Science, Bijie 551700, China. (qiailili@yeah.net).

Aili Qi (Correspondence Author) is an associate professor in Guizhou University of Engineering Science, Bijie 551700, China. (qiailili@yeah.net).

Article submitted 2020-09-13. Resubmitted 2020-10-02. Final acceptance 2020-10-02. Final version published as submitted by the authors. 